Fetal Diagnosis and Therapy

\title{
Fetal Myelomeningocele Closure: Technical Considerations
}

\author{
Gregory G. Heuer ${ }^{a, c}$ N. Scott Adzick ${ }^{b, c}$ Leslie N. Sutton ${ }^{a, c}$ \\ Divisions of a Neurosurgery and ${ }^{b}$ Pediatric General, Thoracic, and Fetal Surgery and ${ }^{c}$ Center for Fetal Diagnosis \\ and Treatment, Children's Hospital of Philadelphia, Philadelphia, Pa., USA
}

\section{Key Words}

Fetal surgery $\cdot$ Myelomeningocele $\cdot$ Dermoid .

Inclusion cysts · MOMS trial

\begin{abstract}
Myelomeningocele (MMC) is one of the most common serious congenital malformations. Typically this condition has been treated with closure of the MMC defect shortly after birth. In general, surgery for MMC aims to provide a multilayered closure to provide protection to the neural elements, prevent leakage of spinal fluid and reduce infection risks. A randomized controlled trial, the Management of Myelomeningocele Study (MOMS), has shown that closure during the fetal period can be performed relatively safely and can result in significant benefit to the child. Whereas the surgical technique of prenatal closure of an MMC defect is similar to a postnatal closure, there are some important technical differences. The goal of this paper is to describe the technique of fetal closure of MMC defects, highlight the unique steps that are needed for this surgery and delineate some potential pitfalls.
\end{abstract}

๑) 2014 S. Karger AG, Basel

\section{Introduction}

Despite advances in prevention, diagnosis and intervention, neural tube defects remain a major source of morbidity and mortality in the USA and throughout the world. Myelomeningoceles (MMCs) occur with an inci- dence of less than 1 per 1,000 live births in the USA [1]. Most MMC lesions are discovered prior to birth, leading to the possibility for prenatal closure of these lesions. Successful open fetal surgery for MMCs was first described in the late 1990s [2]. Fetal surgery was subsequently performed in a small group of patients, with preliminary data suggesting potential benefit $[3,4]$. These promising results led to a randomized controlled trial: the Management of Myelomeningocele Study (MOMS) [5]. Three fetal surgery centers participated (the Children's Hospital of Philadelphia, Vanderbilt University and the University of California, San Francisco) with a pediatric neurosurgeon at each institution performing the fetal closure along with a dedicated team. Although the exact technique varied among the surgeons, the essentials of the closure were standardized. The results were published in 2011 and demonstrated a reduced need for ventricular diversion procedures, a reduction in the rate of hindbrain herniation and an improvement in neurological function and ambulation in patients who underwent prenatal compared with those who had postnatal closure. Fetal closure of an MMC is technically more challenging than the standard postnatal closure. The access is smaller, since the surgeon must work through a small uterine window; the structures are smaller and more delicate; the placode must be handled with more care, since it is potentially functional; avoiding blood loss is critical, since a fetal transfusion is best avoided, and the surgery must be performed quickly to limit the exposure of the fetus to the extrauterine environment. Furthermore, the neurosur-

\section{KARGER 125}

(c) 2014 S. Karger AG, Base

$1015-3837 / 14 / 0373-0166 \$ 39.50 / 0$
Gregory G. Heuer, MD, PhD

Division of Neurosurgery, Children's Hospital of Philadelphia Wood Center, 6th Floor, 34th Street and Civic Center Boulevard Philadelphia, PA 19104 (USA)

E-Mail heuerg@email.chop.edu 
geon must function as part of a team. The closure must be temporarily halted if there is fetal distress or compromise of umbilical blood flow, and resumed once the issues have been resolved. This requires constant communication between the neurosurgeon, the fetal surgeon, the maternal-fetal medicine specialist, the anesthesiologist, the fetal cardiologist, and the nursing staff.

\section{Prenatal Evaluation}

Presurgical studies in the fetal MMC patient are reviewed by the entire fetal team. The inclusion and exclusion criteria set out in the MOMS trial are still employed at our institution, pending future studies [5]. The fetal MRI is used primarily to assess the degree of hindbrain herniation and to evaluate the fetal brain and spinal cord anatomy. As a rule, neuroradiological findings consistent with MMC, such as ventricular heterotopias and thinning of the corpus callosum, are not considered contraindications to fetal surgery. The presence of a syrinx should be considered on an individual basis. Theoretically, reversal of hindbrain herniation with fetal surgery might actually improve a syrinx, but further study of this issue is needed. The fetal ultrasound is used to evaluate the fetus for other anomalies, assess leg and foot movement, define the bony level and skin level of the MMC lesion, and define the presence or absence of a sac (MMC and myeloschisis, respectively). It is essential to exclude skin-covered lesions such as myelocystocele, lipomyelomeningocele and myelocele, since these are not appropriate for fetal intervention. The absence of hindbrain herniation and hydrocephalus, a thick-walled sac, and normal values of amniotic fluid $\alpha$-fetoprotein and acetylcholinesterase strongly suggest a skin-covered dysraphism [6].

Imaging studies are useful in surgical planning [7-9]. The fetus with a wide defect and no sac (myeloschisis) may present difficulty in closing the skin, and a graft may be required and should be available and prepared. A significant kyphosis excludes the patient from fetal surgery, as this may make a safe closure impossible [5].

\section{Fetal Team}

Prenatal surgery requires a coordinated effort from a number of people (table 1) [10]. This team includes an anesthesia team with special training in fetal surgery and an understanding of both fetal and maternal anesthesia needs. Fetal cardiology is present to monitor the fetal
Table 1. Fetal surgery team

\begin{tabular}{ll}
\hline Team member & Role \\
\hline Anesthesia & Delivery of anesthesia - maternal and fetal \\
\hline Fetal cardiology & $\begin{array}{l}\text { Monitoring fetal heart rate and function by } \\
\text { fetal echocardiography }\end{array}$ \\
\hline $\begin{array}{l}\text { Maternal-fetal } \\
\text { medicine/obstetrics }\end{array}$ & $\begin{array}{l}\text { Monitoring maternal and fetal health, } \\
\text { performing fetal version when needed prior } \\
\text { to hysterotomy, intraoperative ultrasound }\end{array}$ \\
\hline Neurosurgery & MMC closure \\
\hline Fetal surgery & $\begin{array}{l}\text { Hysterotomy and closure, stabilization of } \\
\text { the fetus within the surgical field, fetal } \\
\text { resuscitation when needed, MMC closure, } \\
\text { maternal laparotomy and closure }\end{array}$ \\
\hline $\begin{array}{l}\text { Scrub and } \\
\text { circulating nurses }\end{array}$ & $\begin{array}{l}\text { Assisting with surgical procedure } \\
\text { Perfusionist }\end{array}$ \\
$\begin{array}{l}\text { Delivery and control of the Level 1 infusion } \\
\text { device for amniotic fluid replacement to } \\
\text { keep the fetus warm and buoyant and to } \\
\text { avoid umbilical cord compression }\end{array}$ \\
\hline
\end{tabular}

heart rate and function using fetal echocardiography, variables that can be affected by fetal manipulation and anesthesia. A maternal-fetal medicine obstetric team is present to monitor the mother, manipulate the fetus and aid in the selection of the hysterotomy location. The nursing team prepares fetal resuscitation drugs in case they are needed, and prepares a graft if it is likely to be needed. The fetal surgeons perform the hysterotomy, provide access to the fetal spine and perform the maternal laparotomy and closure. The neurosurgery team performs the MMC closure with a fetal surgeon as cosurgeon.

\section{Closure}

Once the hysterotomy is accomplished with a uterine stapling device, the fetus is positioned to present the MMC defect within the hysterotomy site, and the fetus is held by a member of the fetal surgery team (fig. 1a). Care is taken to stabilize the fetus without excessive pressure which can lead to fetal bradycardia and diminished fetal cardiac function. The umbilical cord is located to a safe position, and the Level 1 infusion device (Smiths Medical, St. Paul, Minn., USA) is used to keep the fetus warm and buoyant.

A narcotic and muscle relaxant mixture is injected intramuscularly into the fetus to provide supplemental anesthesia. The MMC closure is performed in a manner sim- 
Fig. 1. Fetal MMC closure. a Stabilization of the fetal back and MMC within the hysterotomy. b Incision in the skin surrounding the defect, outside of the zona epithelioma and within full-thickness skin. c Dissection of the arachnoid and residual epithelial tissue from the placode. d Incision in the lateral myofascial layer and medial rotation over the placode. e Closure of the myofascial layer; note: the area containing the mobilized bone at the left is not yet closed (black arrows). $\mathbf{f}$ Closure of the skin layer.
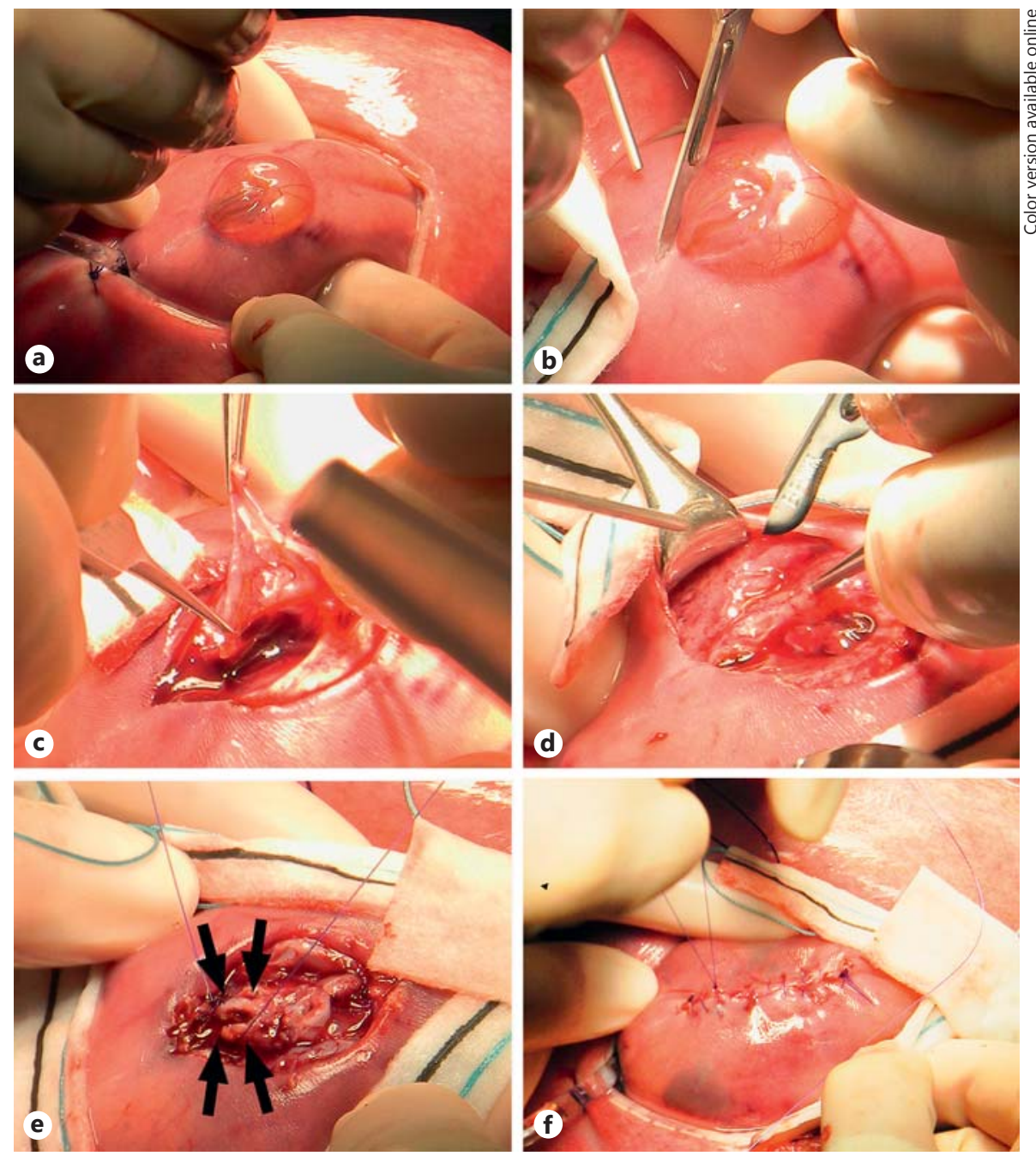

ilar to that used for a standard postnatal closure $[1,10$ 12]. The skin surrounding the defect is incised to the level of the fascia with a vertical ellipse located outside of the zona epithelioma and within full-thickness skin (fig. 1b). The sac is mobilized circumferentially using gentle traction and a number $15 \mathrm{knife}$ blade. All of the epithelialized skin is sharply excised from the placode using iris scissors, cutting into the arachnoid that surrounds the placode and releasing the connection to the sac circumferentially. After releasing the placode along with the rostral spinal cord from the sac, the tissue surrounding the placode is inspected, trimming any additional tissue that looks epidermal (fig. 1c). Residual epithelial tissue may increase the risk of epidermoid/dermoid inclusion cyst formation. As a rule, no attempt is made to 're-neurulate' the placode. The fetal placode is quite soft and delicate, and manipulation produces trauma to potentially functional nervous tissue. A sheet of Seprafilm (Genzyme, Cambridge, Mass., USA) may be placed over the placode to provide an adhesion barrier and possibly reduce tethering, although the value of this maneuver is unproven.

A multilayered closure is performed as in a standard postnatal closure. If present, the dura is mobilized laterally from its attachment to the underlying fascia and reflected over the placode. It is then sutured in the midline using a running 4-0 polydioxanone (PDS) stitch (Ethicon, Somerville, N.J., USA). Some surgeons may choose to augment the closure with a dural substitute such as DuraGen (Integra, Plainsboro, N.J., USA). In many cases, a distinct dural layer may not be large enough to provide a secure closure, and thus may have to be incorporated with the myofascial layer.

The skin is extensively undermined laterally by spreading with a Metzenbaum scissors to allow exposure of the 


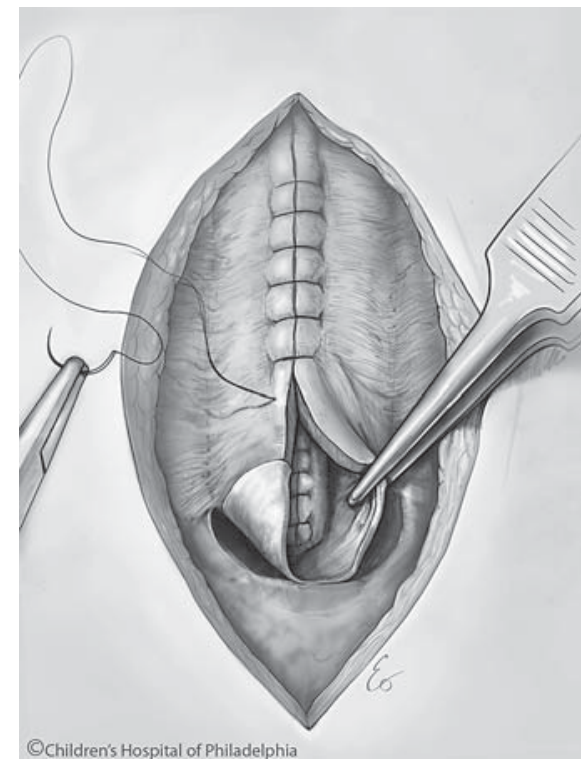

Fig. 2. Representation of the rotation of the myofascial flaps. Note the mobilization of the osteoplastic portion at the inferior edge of the wound (grasped by the forceps).

myofascial layer and to later allow for mobilization of the skin edges and skin wound closure. Small blood vessels on the surface of the fascia are coagulated with bipolar cautery. Bilateral elliptical incisions are made in the lateral myofascial layer (fig. 1d), which are then undermined and reflected over the dura. This may be done with a fresh number $15 \mathrm{knife}$ blade. In cases of lower lumbar or sacral MMCs, the fascial layer may be absent at its inferior extent. The myofascial incision is then carried down to the everted facet joint and the incision is carried into the joint with the number 15 blade. Thus, an osteoplastic flap is created containing thin bone and joint cartilage along with the myofascial flap (fig. 1e). The myofascial flap is closed with a running 4-0 PDS stitch over the dural closure (fig. 2). The edges of the skin are trimmed to healthy tissue for closure. The skin can be difficult to approximate, especially if the defect is $3 \mathrm{~cm}$ or more in maximal transverse width. The skin is extremely thin in the fetus less than 23 weeks' gestation, and special care is required. 'Pinching' the skin together from the sides of the fetus can assist the closure. However, this maneuver is not always tolerated by the fetus and can lead to bradycardia. If too much tension is applied along the skin closure suture line, the delicate fetal skin can tear, requiring additional sutures. Unlike postnatal closure, the thin fetal skin requires a larger full-thickness suture to prevent the suture from tearing the skin. The skin is closed as a single layer with a running
4-0 PDS stitch (fig. 1f). The closure can be aided by utilizing a 'lacing' technique. The running suture is placed after tying an anchor stitch at one end, but the running stitch is left loose with the other end untied. Using a right-angle nerve hook, the sutures are gradually tightened from the anchor stitch end as forceps are used to maintain tension on the running suture. This technique dissipates the force gradually along the suture line and reduces the likelihood that the sutures will tear through the skin.

Large skin defects, especially when there is no sac (myeloschisis), cannot be closed primarily. In our institution, an elliptical-shaped AlloDerm graft (LifeCell, Branchburg, N.J., USA) is sutured to the edge of the skin defect with a continuous 4-0 PDS suture. The graft usually heals well, there is ingrowth of fetal skin tissue into the graft, and at birth it provides a protective layer that does not usually require revision. We have avoided rotation flaps and relaxing incisions to mobilize skin flaps, but these techniques have been employed by others. The hysterotomy site and maternal laparotomy are closed by the fetal team. The mother is then stabilized and returned to her room in the immediately adjacent Special Delivery Unit at the Children's Hospital of Philadelphia.

\section{Special Considerations}

\section{Fetoscopy}

Because of the inherent risk of open fetal surgery through a hysterotomy, less invasive techniques such as fetoscopy have been attempted [11]. Early in the development of fetal surgery for MMC, endoscopic techniques were employed for closure in animal models [12]. The first attempt to close a human fetal MMC was reported in 1997 utilized an endoscopic technique to place a maternal skin graft over the MMC defect [13]; 2 of the 4 fetuses died and no benefit to the remaining fetuses was demonstrated. More recently, others have reported using fetoscopic techniques $[14,15]$. It is believed that a watertight closure is important to provide a clinical benefit to the fetus, and it is difficult to achieve this goal using current endoscopic techniques. Additionally, endoscopic techniques using multiple fetoscopic ports are associated with an increased incidence of premature rupture of membranes and very premature birth. A study from Europe published in 2013 described 19 patients with endoscopic fetal MMC closure [16]; 3 fetal deaths occurred, 3 surgeries were discontinued due to hemorrhage, and 13 surgeries were completed. Neurological benefit was difficult to demonstrate. If the technical difficulties with prematurity and graft place- 
Fig. 3. Resection of epidermoid inclusion cyst in a child years after a fetal MMC closure. a Dissection of the AlloDerm graft placed at the time of fetal MMC closure. b Appearance after opening of the dura. The spinal cord is seen at the left (black arrowhead) and the attachment of the graft through the fascia to the cord can be seen (white arrowhead). c Resection of the epidermoid material (black arrowhead). d Appearance after dural closure.
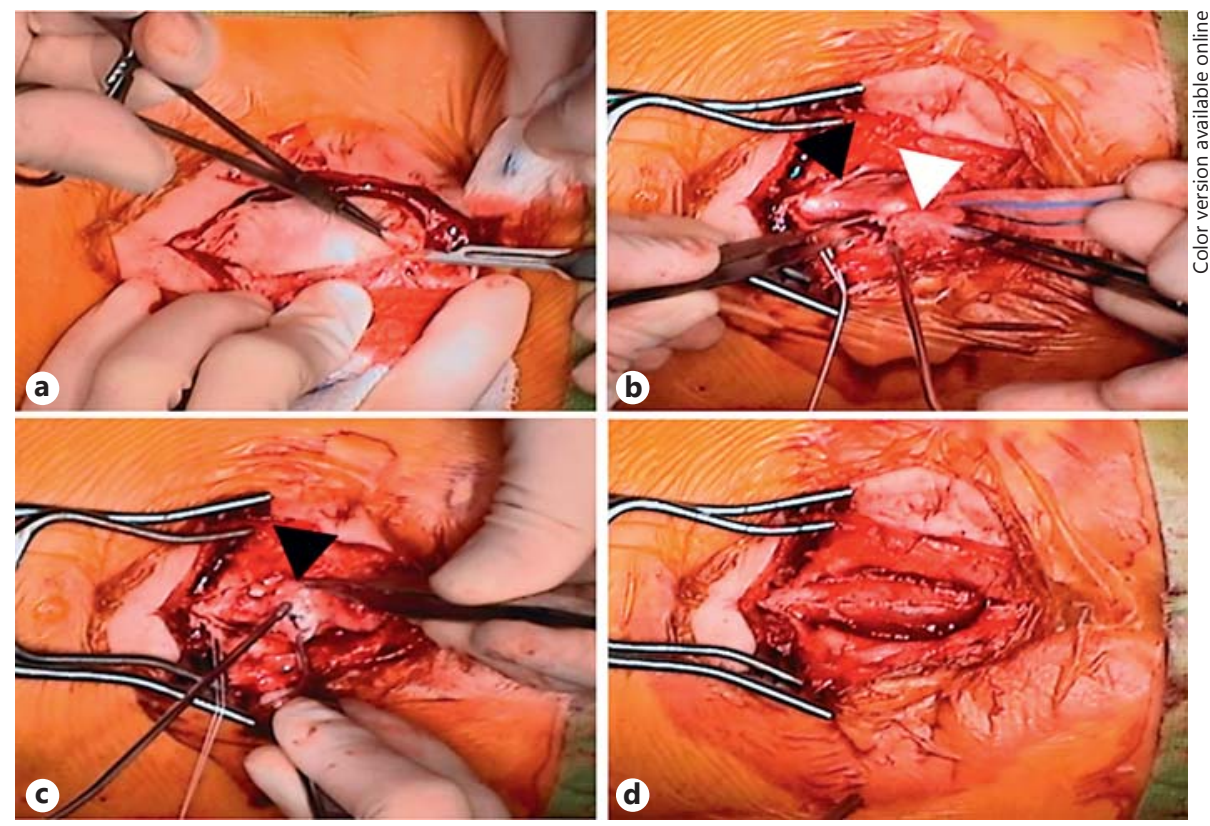

ment can be overcome, these strategies could eventually prove useful [17].

Further advances are being made that may make fetoscopy-based techniques more practical. The development of tissue glues and bioengineering strategies may allow less invasive closure techniques [18-21]. While these hold promise, they are still experimental, and it will be important to show they are feasible in small and large animal models and carefully designed human studies before they are widely employed.

\section{Postnatal Inclusion Cysts}

Dermoid and epidermoid inclusion cysts at the closure site have been described following fetal MMC closure [22, 23]. The patients presented with neurological decline and tenderness at the closure site, and were found on MRI to have epidermoid inclusion cysts. In some cases, the child has presented with wound breakdown or drainage several months or years after the closure, and the cyst has actually burrowed through the dural and fascial closure to the level of the skin. In other cases, the cysts may be related to use of AlloDerm, as they appear physically to be adherent to graft material, although inclusion cysts can occur in patients where AlloDerm was not used. Another theory is that the inclusion cysts arise from residual rests of epithelial tissue attached to the placode following the surgical closure, since they may be seen in postnatal closures as well [24-29]. It is not known if there is something unique about the fetal spine milieu that promotes growth of epithelial tissue, or if the apparent increased incidence following fetal closures is an epiphenomenon related to the increased function in these patients allowing more to be found. In the MOMS trial there was no statistical difference in cyst occurrence between prenatal and postnatal closure, but the numbers were small [5].

The resection of these lesions is difficult compared to surgery for inclusion cysts not associated with fetal MMC closure. In part, this is because of involvement of the cyst with the overlying skin. The surgery should be performed with neuromonitoring including motor-evoked potentials, as former fetal patients often have significant functional nerves below the level of the placode and cyst [30]. If a graft was used, the entire AlloDerm graft is circumferentially incised and dissected laterally down to the fascial level (fig. 3a). The cyst may be intimately attached to the overlying skin or graft, and it is best to resect the cyst and the involved skin together. Once the lateral fascia is identified, the overlying soft tissues are dissected medially until the fascial defect is well defined. A laminectomy is performed above the dorsal spinal defect and the normal dura is identified. The dura is then opened and followed inferiorly to the cyst, with an attempt to identify the normal spinal cord, nerve roots and previous placode (fig. $3 \mathrm{~b}$ ). The normal dura is followed inferiorly and stay sutures are placed to maintain the dural edge as the lateral lines of attachment are divided, as is done with a dorsal lipomyelomeningocele. The normal nerve roots are usually ventral to this line of attachment. The anatomy of these lesions can 
be very distorted and careful study of the preoperative MRI is essential. Intermittent electrical stimulation of tissue is frequently performed to identify any nerve tissue prior to cutting the attachments. Eventually, the dura is found to reconstitute inferiorly, and any caudal tethering is released.

The goal of the surgery is to untether the spinal cord and resect the contents of the inclusion cyst (fig. 3c). It is not sufficient to only remove the superficial portion of the cyst without untethering the cord at the same time. It does not appear necessary to resect the entire cyst wall, but merely to resect the keratin contents of the cyst. This may be a unique feature of the fetal MMC closure-derived inclusion cyst, since they rarely if ever recur, even with subtotal removal.

The final step is dural and skin closure (fig. 3d). The closure can be difficult, as often there are large dural and skin defects after resection. The assistance of a plastic surgery team is often needed to provide adequate skin closure. This may require rotation of a vascularized myocutaneous flap, or in some cases lateral or bilateral relaxation incisions are used.

\section{Conclusion}

Fetal MMC closure can be an effective management strategy for selected MMC patients, resulting in significant benefit to these patients. The surgery must be performed with maximal safety and few complications. The closure is similar to postnatal closure, but there are important differences in technique that are the key to an acceptable outcome.

\section{References}

1 Bauman JA, Schwartz DM, Welch WC, Sutton LN: in Herkowitz HN, et al (eds): Rothman-Simeone the Spine. Philadelphia, Saunders, 2011, vol 1, chapt 31, pp 573-607.

$\checkmark 2$ Adzick NS, Sutton LN, Crombleholme TM, Flake AW: Successful fetal surgery for spina bifida. Lancet 1998;352:1675-1676.

$>3$ Sutton LN, et al: Improvement in hindbrain herniation demonstrated by serial fetal magnetic resonance imaging following fetal surgery for myelomeningocele. JAMA 1999;282: 1826-1831.

4 Bruner JP, et al: Fetal surgery for myelomeningocele and the incidence of shunt-dependent hydrocephalus. JAMA 1999;282:1819-1825.

5 Adzick NS, et al: A randomized trial of prenatal versus postnatal repair of myelomeningocele. New Engl J Med 2011;364:993-1004.

6 Midrio P, Silberstein HJ, Bilaniuk LT, Adzick NS, Sutton LN: Prenatal diagnosis of terminal myelocystocele in the fetal surgery era: case report. Neurosurgery 2002;50:1152-1154, discussion 1154-1155.

7 Husler MR, et al: Prenatal diagnosis and postnatal outcome of fetal spinal defects without Arnold-Chiari II malformation. Prenat Diagn 2009;29:1050-1057.

-8 Mangels KJ, Tulipan N, Tsao LY, Alarcon J, Bruner JP: Fetal MRI in the evaluation of intrauterine myelomeningocele. Pediatr Neurosurg 2000;32:124-131.

-9 Chao TT, et al: Fetal spine findings on MRI and associated outcomes in children with open neural tube defects. AJR Am J Roentgenol 2011;197:W956-W961.

10 Gupta N, Farrell JA, Rand L, Cauldwell CB, Farmer D: Open fetal surgery for myelomeningocele. J Neurosurg Pediatrics 2012;9:265-273.

$>11$ Yang EY, Adzick NS: Fetoscopy. Semin Laparosc Surg 1998;5:31-39.
12 Copeland ML, Bruner JP, Richards WO, Sundell HW, Tulipan NB: A model for in utero endoscopic treatment of myelomeningocele. Neurosurgery 1993;33:542-544, discussion 545.

13 Bruner JP, Richards WO, Tulipan NB, Arney TL: Endoscopic coverage of fetal myelomeningocele in utero. Am J Obstet Gynecol 1999;180:153-158.

14 Kohl T, Gembruch U: Current status and prospects of fetoscopic surgery for spina bifida in human fetuses. Response to Fichter et al: Fetal spina bifida repair - current trends and prospects of intrauterine neurosurgery (Fetal Diagn Ther 2008;23:271-286). Fetal Diagn Ther 2008;24:318-320.

15 Farmer DL, et al: In utero repair of myelomeningocele: experimental pathophysiology, initial clinical experience, and outcomes. Arch Surg 2003;138:872-878.

16 Verbeek RJ, et al: Fetal endoscopic myelomeningocele closure preserves segmental neurological function. Dev Med Child Neurol 2012; 54:15-22.

17 Adzick NS: Fetal surgery for spina bifida: past, present, future. Semin Pediatr Surg 2013;22: 10-17.

18 Eggink AJ, et al: In utero repair of an experimental neural tube defect in a chronic sheep model using biomatrices. Fetal Diagn Ther 2005;20:335-340

19 Watanabe $M$, et al: A tissue engineering approach for prenatal closure of myelomeningocele with gelatin sponges incorporating basic fibroblast growth factor. Tissue Eng Part A 2010;16:1645-1655.

20 Watanabe $\mathrm{M}$, et al: A tissue engineering approach for prenatal closure of myelomeningocele: comparison of gelatin sponge and microsphere scaffolds and bioactive protein coatings. Tissue Eng Part A 2011;17:1099-1110.
21 Fontecha CG, et al: Fetoscopic coverage of experimental myelomeningocele in sheep using a patch with surgical sealant. Eur J Obstet Gynecol Reprod Biol 2011;156:171-176.

22 Danzer E, et al: Intradural inclusion cysts following in utero closure of myelomeningocele: clinical implications and follow-up findings. J Neurosurg Pediatr 2008;2:406-413.

23 Mazzola CA, et al: Dermoid inclusion cysts and early spinal cord tethering after fetal surgery for myelomeningocele. New Engl J Med 2002;347:256-259.

24 Iwasaki M, Yoshida Y, Shirane R, Yoshimoto T: Spinal dermoid cyst secondary to myelomeningocele repair: a case report (in Japanese). No Shinkei Geka 2000;28:155-160.

25 Kirsch WM, Hodges FJ 3rd: An intramedullary epidermal inclusion cyst of the thoracic cord associated with a previously repaired meningocele. Case report. J Neurosurg 1966; 24:1018-1020.

26 Scott RM, Wolpert SM, Bartoshesky LE, Zimbler S, Klauber GT: Dermoid tumors occurring at the site of previous myelomeningocele repair. J Neurosurg 1986;65:779-783.

27 Martinez-Lage JF, Masegosa J, Sola J, Poza M: Epidermoid cyst occurring within a lumbosacral myelomeningocele. Case report. J Neurosurg 1983;59:1095-1097.

28 Storrs BB: Are dermoid and epidermoid tumors preventable complications of myelomeningocele repair? Pediatr Neurosurg 1994;20: $160-162$.

29 Chadduck WM, Roloson GJ: Dermoid in the filum terminale of a newborn with myelomeningocele. Pediatr Neurosurg 1993;19:81-83.

30 Jackson EM, et al: Intraoperative neurophysiological monitoring in patients undergoing tethered cord surgery after fetal myelomeningocele repair. J Neurosurg Pediatr 2014;13:355-361.
Fetal Myelomeningocele Closure:

Technical Considerations 